\section{Ocular findings in patients with solid tumours treated with the epidermal growth factor receptor tyrosine kinase inhibitor gefitinib ('Iressa', ZD1839) in Phase I and II clinical trials}

\begin{abstract}
Purpose To describe the strategy used for large-scale ophthalmological monitoring in the clinical development of the novel anticancer agent gefitinib ('Iressa', ZD1839), an epidermal growth factor receptor tyrosine kinase inhibitor, which had demonstrated ocular effects in preclinical animal models. Methods In this extensive clinical trial programme, patients in Phase I and II trials underwent frequent and intensive ophthalmological monitoring at baseline and during the trials. Data were reviewed by an external independent Ophthalmology Advisory Board.

Results Ophthalmological data for 221 patients in Phase I trials of gefitinib and 425 patients in Phase II trials revealed no evidence of any consistent or drug-related ophthalmological toxicity. Interestingly, the baseline data revealed that, in an asymptomatic population, transient ophthalmological events are identified during monitoring.

Conclusions This study reports the methodology and normative data in an ophthalmological screening programme that should prove useful for future studies. Eye (2005) 19, 729-738. doi:10.1038/sj.eye.6701630; published online 28 January 2005
\end{abstract}

Keywords: cancer; EGFR; gefitinib; Iressa; ZD1839
AB Tullo', B Esmaeli², PI Murray ${ }^{3}$, E Bristow ${ }^{4}$,

BJ Forsythe ${ }^{5}$ and K Faulkner ${ }^{5}$
Introduction

There are currently no data on the spectrum of ocular surface abnormalities in asymptomatic adults, as large-scale ophthalmological monitoring is not routinely carried out in most clinical trials. Here, we present baseline data from a large clinical trial programme of a novel anticancer agent in which patients underwent frequent biomicroscopic monitoring of the ocular surface.

Gefitinib ('Iressa', ZD1839) is an orally active epidermal growth factor receptor tyrosine kinase inhibitor (EGFR-TKI) that shows reversible cell growth inhibition in vitro and evidence of antitumour activity in clinical trials. In preclinical toxicity studies of gefitinib $40 \mathrm{mg} / \mathrm{kg} /$ day in rats and dogs, reversible thinning of corneal epithelium was observed in both species after 1 and 6 months. ${ }^{1}$

Furthermore, in dogs treated with the highest dose of gefitinib for 6 months, the corneal opacification first observed at 1 month progressed on treatment and did not reverse during a 3-month withdrawal period. ${ }^{1}$ Moreover, other EGFR inhibitors have caused similar corneal changes in preclinical models. ${ }^{2,3}$

These preclinical findings are consistent with the pharmacological actions of gefitinib. The EGFR is strongly expressed in the basal epithelial cells of limbal and conjunctival epithelia and throughout the corneal epithelium; however, little or no EGFR is seen in the superficial conjunctival or limbal epithelia,
${ }^{1}$ Royal Eye Hospital

Manchester, UK

${ }^{2}$ Ophthalmology Section The University of Texas MD Anderson Cancer Center, Houston, TX, USA

${ }^{3}$ University of Birmingham Birmingham, UK

${ }^{4}$ Royal Victoria Infirmary Newcastle upon Tyne, UK

${ }^{5}$ AstraZeneca

Macclesfield, UK

Correspondence:

A Tullo,

Manchester Royal Eye

Hospital,

Oxford Road,

Manchester M13 9WH, UK Tel: + 44 (0)161 276 5522; Fax: + 44 (0)161 2726618 .

E-mail: Andrew.Tullo@ CMMC.nhs.uk

Published online: 28 January 2005 
demonstrating that EGFR is preferentially expressed in basal epithelial cells that have the greatest proliferative potential. ${ }^{4}$ The EGFR ligand, EGF, promotes migration and proliferation of epithelial cells, thus facilitating corneal epithelial wound healing. ${ }^{5}$ Furthermore, endogenous EGF is synthesised by the lacrimal gland in response to corneal epithelial injury. ${ }^{6}$ EGF is found in high concentrations in tears ${ }^{7}$ and is important for normal ocular homeostasis. ${ }^{8}$

The preclinical results combined with the known ocular importance of the EGFR warranted ophthalmological monitoring during clinical trials of gefitinib. The initial dose-ranging Phase I trials of gefitinib were designed to determine its dose-limiting toxicity in patients with a range of advanced solid tumours. In these trials, patients underwent intensive and frequent ophthalmological monitoring. The monitoring procedures were reviewed and modified after the first trial (Trial 5). The data from all three Phase I trials were reviewed by an independent external Ophthalmology Advisory Board to determine the level of monitoring required in subsequent trials, including two large Phase II trials to investigate the antitumour activity of gefitinib monotherapy in advanced non-small-cell lung cancer (NSCLC). The advisory board constituted leading US and European ophthalmologists with expertise of both the cornea and drug-development issues. They were consulted prior to and during these Phase I studies and on an ad hoc basis for specific advice.

Here, we report the ocular findings in three Phase I, dose-escalation, multicentre trials of oral monotherapy gefitinib at doses up to $1000 \mathrm{mg} /$ day in 221 patients with a range of solid malignancies (Trials 5, 11, and 12) ${ }^{9-11}$ and 425 patients enrolled in two Phase II trials of gefitinib at two doses in patients with advanced NSCLC (IDEAL ['Iressa' Dose Evaluation in Advanced Lung cancer] 1 and 2). ${ }^{12,13}$ Ocular data from these multicentre trials were standardised using pro forma ophthalmology records, with training given in assessment and documentation at study start-up (see Figure 1 for extensive ophthalmological parameters assessed). Clinically significant ophthalmological changes were reported as adverse events and discussed in depth with trial centre personnel when necessary, to obtain more information on the individual cases from a safety surveillance perspective and to ensure events were being described consistently.

\section{Materials and methods}

\section{Phase I trials}

Treatment

In the initial Phase I trial, gefitinib was administered once daily for 14 days followed by 14 days of observation in

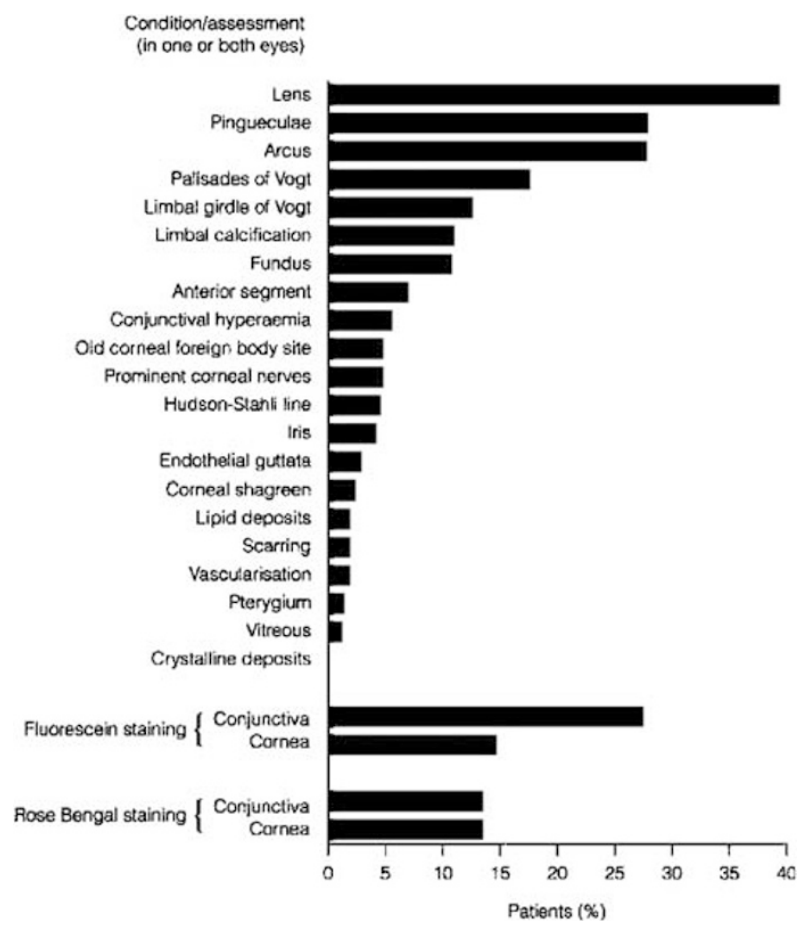

Figure 1 Baseline findings of slit-lamp examination in Phase I trials. Anterior segment includes iridoschisis, lower lid ptosis, blind shrunken eye since childhood, keratitic precipitates, lower lid notching, and loss of lashes; Iris includes dyscoria, prominent iris vessel, and synechiae; Lens includes cataract, opacity, and nuclear sclerosis; Fundus includes drusen, naevi, disc cupping, chorio-retinal atrophy, and diabetic retinopathy; Vitreous includes asteroid hyalosis.

28-day cycles (Trial 5). The subsequent Phase I trials were conducted using 28-day cycles of once-daily oral dosing (Trials 11 and 12). A range of different doses was used and for simplicity they have been grouped into four dose ranges, as follows: $<225 \mathrm{mg} /$ day $(50,100$, and $150 \mathrm{mg} /$ day); $250 \mathrm{mg} /$ day (225 and $300 \mathrm{mg} /$ day); $\sim 500 \mathrm{mg} /$ day (400 and $525 \mathrm{mg} /$ day); and $>525 \mathrm{mg} /$ day $(600,700,800$, and $1000 \mathrm{mg} /$ day $)$.

\section{Patients}

Ophthalmological exclusion criteria were established in discussion with the independent Ophthalmology Advisory Board. These were: abnormality of cornea (other than scars, congenital abnormality or corneal tearfilm insufficiency); currently receiving drugs with known corneal toxicity (eg hydroxychloroquine, amiodarone, tamoxifen, and chlorpromazine); history of dry-eye syndrome (eg Sjögren's syndrome); history of ocular surface abnormality (including Stevens-Johnson syndrome and alkali burns); eyes within a previous radiotherapy field; and current use of contact lenses (previous contact lens wearers were eligible if their eye examination was within normal limits). 


\section{Assessments}

Ophthalmological assessments were established in discussion with the Ophthalmology Advisory Board. An ophthalmological examination was performed routinely at baseline, at Days 14 and 28 of each treatment period and on completion/withdrawal from the trial. This assessment included visual acuity, using a LogMAR illuminated distance vision or Snellen chart, and slitlamp examination with fluorescein and Rose Bengal staining of the cornea and conjunctiva, including lid eversion to quantify tarsal conjunctival hyperaemia. Schirmer's test was used to measure the ability to produce tears over a 3-min period and patients were recorded as having $0-5,>5-10$ or $>10 \mathrm{~mm}$ of tears. Intraocular pressures were also recorded. In addition to routine monitoring, patients were assessed in the event of any ocular abnormalities or symptoms occurring between study visits.

Trial medication was to be stopped if a patient developed punctate staining with symptoms, conjunctival hyperaemia $>1$ quadrant or other objective findings considered more severe than this, for example, corneal epithelial defects or ulceration. Any clinically significant ophthalmological changes were recorded as adverse events using the National Cancer Institute Common Toxicity Criteria (NCI-CTC) version 2.0 (Table 1$).{ }^{14}$

\section{Phase II trials}

In the absence of any consistent or significant ocular toxicity from the Phase I data, the Ophthalmology Advisory Board recommended that for the Phase II trials the inclusion/exclusion criteria could be relaxed and the level of monitoring could be substantially reduced, as any indicators of potential ocular toxicity were associated with easily recognised symptoms. Due to the observation of a few cases of aberrant lashes in Phase I trials, it was also recommended that investigators and patients should be made aware of potential corneal damage resulting from abnormal eyelash growth.

\section{Treatment}

In each of the Phase II trials, patients with previously treated but recurring NSCLC received oral gefitinib once daily at either 250 or $500 \mathrm{mg} /$ day.

\section{Patients}

Patients were not excluded from these trials for any ocular conditions. However, those patients who had an ocular inflammation or infection had to have been fully treated before entry into the trial. Patients with an increased risk of corneal erosions (eg with a neuropathic keratopathy, diabetes, or anterior basement membrane dystrophy) were assessed frequently by an ophthalmologist during trial treatment.

\section{Assessments}

Following discussions with the Ophthalmology Advisory Board to establish what ophthalmological assessments were required, standard record forms were designed to capture this information. Prior to patient recruitment, training was given on correct assessment and documentation, including reporting of ocular adverse events (irrespective of causality).

An ophthalmological examination was performed routinely at baseline and on completion/withdrawal from the trial. This included assessment of visual acuity, quantification of conjunctival hyperaemia, slit-lamp examination with fluorescein staining, and a Schirmer's test (baseline only).

In the event of subjective symptoms of visual disturbance, eye pain or hyperaemia, trial medication was temporarily interrupted and a slit-lamp examination including eversion of the upper eyelid to check for the degree of hyperaemia, was conducted as soon as possible. Any clinically significant ophthalmological changes were recorded as adverse events using the NCICTC. An adverse event was defined, according to $\mathrm{ICH}$ E2A guidelines, ${ }^{15}$ as the development of a new medical condition or the deterioration of a pre-existing medical condition following or during exposure to trial medication, whether or not considered causally related to the product.

\section{Results}

\section{Phase I trials}

Patients

A total of 221 patients with a wide range of solid tumours and prior anticancer treatments were enrolled in the three Phase I trials (Table 2). The median age (range) of the patients was 58 (27-90) years and half the population was male. The majority $(65.6 \%)$ of patients had a World Health Organization performance status of 1 ('generally healthy but may not be able to do heavy physical work').

\section{Baseline ophthalmological findings}

More than 830 slit-lamp examinations were performed over the course of the three trials. Many patients entered into the trials had ophthalmological findings at baseline (Figure 1, $n=173$ patients). Conjunctival hyperaemia was seen in $6 \%$ of patients at baseline, while the most common findings were pingueculae and arcus, both seen in $28 \%$ of patients. These findings were equally distributed across the dose groups (data not shown). 
Table 1 Definition of ocular/visual adverse events by NCI-CTC grade $^{14}$

\begin{tabular}{|c|c|c|c|c|c|}
\hline & \multicolumn{5}{|c|}{ NCI-CTC grade } \\
\hline & 0 & 1 & 2 & 3 & 4 \\
\hline Cataract & None & Asymptomatic & Symptomatic, partial visual loss & $\begin{array}{l}\text { Symptomatic, visual loss } \\
\text { requiring treatment or } \\
\text { interfering with function }\end{array}$ & - \\
\hline Conjunctivitis & None & $\begin{array}{l}\text { Abnormal ophthalmological } \\
\text { changes, but asymptomatic } \\
\text { or symptomatic without visual } \\
\text { impairment (ie pain and } \\
\text { irritation) }\end{array}$ & $\begin{array}{l}\text { Symptomatic, and interfering } \\
\text { with function, but not interfering } \\
\text { with activities of daily living }\end{array}$ & $\begin{array}{l}\text { Symptomatic, and interfering } \\
\text { with activities of daily living }\end{array}$ & - \\
\hline Dry eye & Normal & Mild, not requiring treatment & $\begin{array}{l}\text { Moderate or requiring artificial } \\
\text { tears }\end{array}$ & - & - \\
\hline Glaucoma & None & $\begin{array}{l}\text { Increase in intraocular pressure } \\
\text { but no visual loss }\end{array}$ & $\begin{array}{l}\text { Increase in intraocular pressure } \\
\text { with retinal changes }\end{array}$ & Visual impairment & $\begin{array}{l}\text { Unilateral or bilateral loss of } \\
\text { vision (blindness) }\end{array}$ \\
\hline $\begin{array}{l}\text { Keratitis (corneal } \\
\text { inflammation/ } \\
\text { corneal ulceration) }\end{array}$ & None & $\begin{array}{l}\text { Abnormal ophthalmological } \\
\text { changes but asymptomatic or } \\
\text { symptomatic without visual } \\
\text { impairment (ie pain and } \\
\text { irritation) }\end{array}$ & $\begin{array}{l}\text { Symptomatic and interfering with } \\
\text { function, but not interfering with } \\
\text { activities of daily living }\end{array}$ & $\begin{array}{l}\text { Symptomatic, and interfering } \\
\text { with activities of daily living }\end{array}$ & $\begin{array}{l}\text { Unilateral or bilateral loss of } \\
\text { vision (blindness) }\end{array}$ \\
\hline $\begin{array}{l}\text { Tearing (watery } \\
\text { eyes) }\end{array}$ & None & $\begin{array}{l}\text { Mild: not interfering with } \\
\text { function }\end{array}$ & $\begin{array}{l}\text { Moderate: interfering with } \\
\text { function, but not interfering with } \\
\text { activities of daily living }\end{array}$ & $\begin{array}{l}\text { Interfering with activities of } \\
\text { daily living }\end{array}$ & - \\
\hline $\begin{array}{l}\text { Vision-blurred } \\
\text { vision }\end{array}$ & Normal & - & $\begin{array}{l}\text { Symptomatic, and interfering } \\
\text { with function, but not interfering } \\
\text { with activities of daily living }\end{array}$ & $\begin{array}{l}\text { Symptomatic, and interfering } \\
\text { with activities of daily living }\end{array}$ & - \\
\hline $\begin{array}{l}\text { Vision-double } \\
\text { vision (diplopia) }\end{array}$ & Normal & - & $\begin{array}{l}\text { Symptomatic, and interfering } \\
\text { with function, but not interfering } \\
\text { with activities of daily living }\end{array}$ & $\begin{array}{l}\text { Symptomatic, and interfering } \\
\text { with activities of daily living }\end{array}$ & - \\
\hline $\begin{array}{l}\text { Vision-flashing } \\
\text { lights/floaters }\end{array}$ & Normal & $\begin{array}{l}\text { Mild, not interfering with } \\
\text { function }\end{array}$ & $\begin{array}{l}\text { Symptomatic, and interfering } \\
\text { with function, but not interfering } \\
\text { with activities of daily living }\end{array}$ & $\begin{array}{l}\text { Symptomatic, and interfering } \\
\text { with activities of daily living }\end{array}$ & - \\
\hline $\begin{array}{l}\text { Vision-night } \\
\text { blindness } \\
\text { (nyctalopia) }\end{array}$ & Normal & $\begin{array}{l}\text { Abnormal electro-retinography } \\
\text { but asymptomatic }\end{array}$ & $\begin{array}{l}\text { Symptomatic, and interfering } \\
\text { with function, but not interfering } \\
\text { with activities of daily living }\end{array}$ & $\begin{array}{l}\text { Symptomatic, and interfering } \\
\text { with activities of daily living }\end{array}$ & - \\
\hline Vision-photophobia & Normal & - & $\begin{array}{l}\text { Symptomatic, and interfering } \\
\text { with function, but not interfering } \\
\text { with activities of daily living }\end{array}$ & $\begin{array}{l}\text { Symptomatic, and interfering } \\
\text { with activities of daily living }\end{array}$ & - \\
\hline $\begin{array}{l}\text { Ocular/visual- } \\
\text { other }\end{array}$ & Normal & Mild & Moderate & Severe & $\begin{array}{l}\text { Unilateral or bilateral loss of } \\
\text { vision (blindness) }\end{array}$ \\
\hline
\end{tabular}


Table 2 Patient demography in the Phase I trials

\begin{tabular}{|c|c|c|c|c|c|}
\hline & \multicolumn{5}{|c|}{ Gefitinib dose level (mg/day) } \\
\hline & $\begin{array}{c}<225 \\
(n=42)\end{array}$ & $\begin{array}{c}\sim 250 \\
(n=69)\end{array}$ & $\begin{array}{c}\sim 500 \\
(n=44)\end{array}$ & $\begin{array}{c}>525 \\
(n=66)\end{array}$ & $\begin{array}{c}\text { All } \\
(n=221)\end{array}$ \\
\hline \multirow[t]{2}{*}{ Age, median (range), years } & 53 & 56 & 59 & 60 & 58 \\
\hline & $(28-72)$ & $(33-76)$ & $(27-81)$ & $(35-90)$ & $(27-90)$ \\
\hline Male/female, $\%$ & $50 / 50$ & $57 / 43$ & $48 / 52$ & $44 / 56$ & $50 / 50$ \\
\hline Performance status $0 / 1 / 2, \%$ & $21 / 71 / 7$ & $29 / 70 / 0^{a}$ & $29 / 64 / 7$ & $41 / 59 / 0$ & $31 / 66 / 3$ \\
\hline \multicolumn{6}{|l|}{ Primary tumour site, $n(\%)$} \\
\hline Breast & $4(9.5)$ & $2(2.9)$ & $1(2.3)$ & $1(1.5)$ & $8(3.6)$ \\
\hline Colorectal & $4(9.5)$ & $7(10.1)$ & $8(18.2)$ & $15(22.7)$ & $34(15.4)$ \\
\hline Gastric & $1(2.4)$ & $0(0.0)$ & $0(0.0)$ & $0(0.0)$ & $1(0.5)$ \\
\hline Head and neck & $5(11.9)$ & $11(15.9)$ & $5(11.4)$ & $5(7.6)$ & $26(11.8)$ \\
\hline NSCLC & $14(33.3)$ & $29(42.0)$ & $15(34.1)$ & $19(28.8)$ & $77(34.8)$ \\
\hline Oesophageal & $0(0.0)$ & $2(2.9)$ & $2(4.5)$ & $0(0.0)$ & $4(1.8)$ \\
\hline Ovarian & $4(9.5)$ & $7(10.1)$ & $7(15.9)$ & $15(22.7)$ & $33(14.9)$ \\
\hline Pancreatic & $1(2.4)$ & $1(1.4)$ & $0(0.0)$ & $0(0.0)$ & $2(0.9)$ \\
\hline Prostate & $1(2.4)$ & $7(10.1)$ & $2(4.5)$ & $9(13.6)$ & $19(8.6)$ \\
\hline Renal & $3(7.1)$ & $1(1.4)$ & $0(0.0)$ & $0(0.0)$ & $4(1.8)$ \\
\hline Sarcoma & $2(4.8)$ & $0(0.0)$ & $1(2.3)$ & $0(0.0)$ & $3(1.4)$ \\
\hline Other & $3(7.1)$ & $2(2.9)$ & $3(6.8)$ & $2(3.0)$ & $10(4.5)$ \\
\hline \multicolumn{6}{|c|}{ Previous cancer treatment, ${ }^{\mathrm{b}} n(\%)$} \\
\hline $\mathrm{CIH}$ & $40(95.2)$ & $61(88.4)$ & $44(100.0)$ & $62(93.9)$ & $207(93.7)$ \\
\hline XRT & $28(66.7)$ & $34(49.3)$ & $22(50.0)$ & $24(36.4)$ & $108(48.9)$ \\
\hline $\mathrm{CIH}+\mathrm{XRT}$ & $28(66.7)$ & $30(43.5)$ & $22(50.0)$ & $21(31.8)$ & $101(45.7)$ \\
\hline Surgery & $11(26.2)$ & $34(49.3)$ & $21(47.7)$ & $45(68.2)$ & $111(50.2)$ \\
\hline Other & $7(16.7)$ & $9(13.0)$ & $4(9.1)$ & $3(4.5)$ & $23(10.4)$ \\
\hline None & $2(4.8)$ & $3(4.3)$ & $0(0.0)$ & $0(0.0)$ & $5(2.3)$ \\
\hline
\end{tabular}

aPerformance status not recorded for one patient in this group.

bows are not mutually exclusive.

$\mathrm{CIH}$, chemotherapy, immunotherapy or hormonal therapy; XRT, radiotherapy.

The most common finding was lens abnormality, often defined as nuclear sclerosis, cataracts or opacities, which was seen in $39 \%$ of patients (Figure 1).

\section{Changes in ophthalmological findings during gefitinib} treatment

Approximately half (106) of the patients had a change from baseline in ophthalmological assessments performed during the trials (Figure 2). Most ophthalmological conditions that developed during the trials were transient, with only $34 \%$ of new ophthalmological events persisting for two or more consecutive assessments. Only $12 \%$ of patients developed conjunctival hyperaemia during the trials, with half of these events being transient.

Schirmer's tests revealed that over half the patients (54\%) had no change in tear production at any time during the trials. Decreased tear production was seen in $41 \%$ of patients overall, with similar results being seen in each of the dose groups (Figure 3).

Ophthalmological events that were considered to be clinically significant were designated 'adverse events'
(Table 3). The most common of these, seen in $>5 \%$ of patients, were conjunctivitis $(14.5 \%$; 31 patients with NCI-CTC grade 1 or 2 and one patient with grade 3$)$, dry eyes $(8.1 \%$; all NCI-CTC grade 1 or 2$)$ and visual disturbance $(7.2 \% ; 15$ patients with NCI-CTC grade 1 or 2 and one patient with grade 3 loss of visual acuity). In general, these adverse events did not appear to be related to either dose or treatment duration, and the majority resolved during the treatment period. However, dry eyes and corneal erosions showed some evidence of being dose related.

A small number of patients experienced adverse events of particular clinical interest with respect to preclinical findings and the pharmacological actions of gefitinib. One patient developed fine bilateral keratitic precipitates, which resolved following cessation of gefitinib. This patient had uveitis and a weakly positive ANA titre, which was treated with steroids. A second patient was described as having a $1 \times 1 \mathrm{~mm}$ left corneal opacity. The underlying cause was not known; however, the opacity was not considered to be drug-related by the reporting physician and was ongoing at the time of 


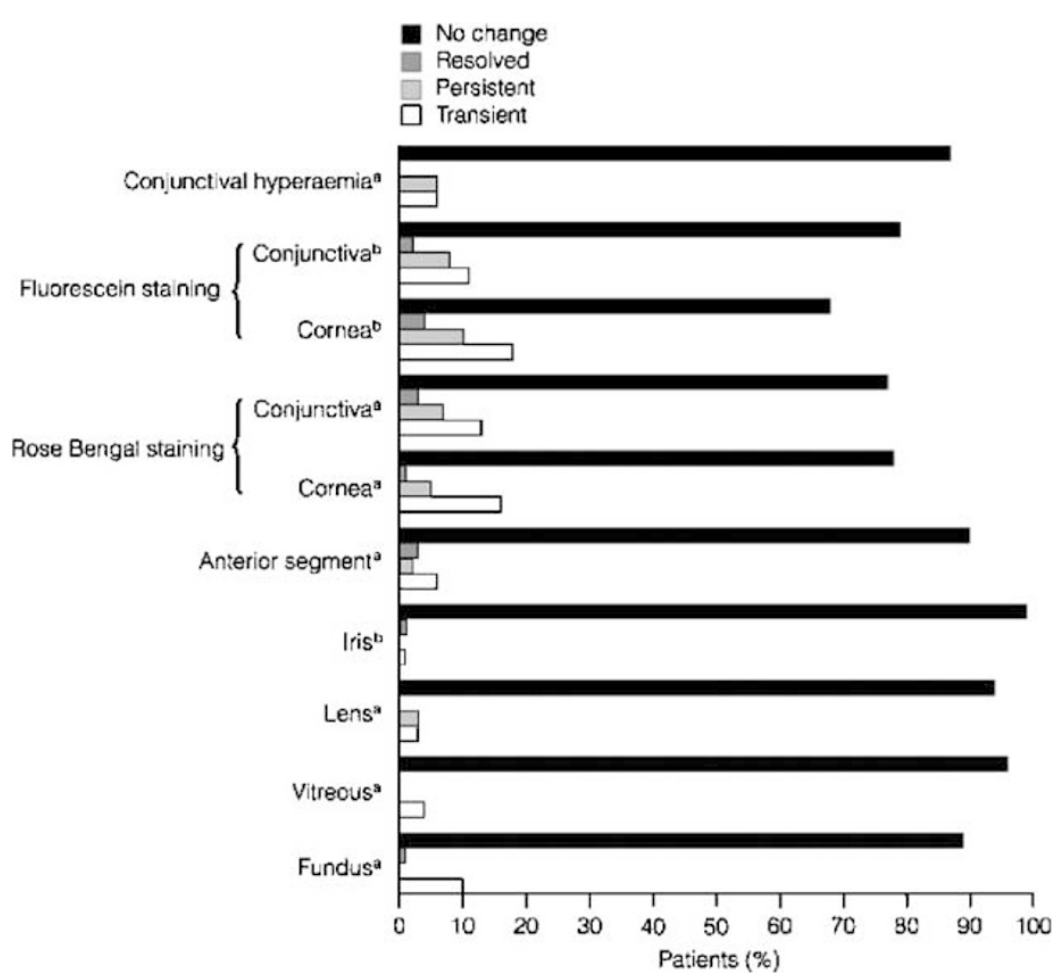

Figure 2 Changes from baseline in staining and additional ophthalmological checks during Phase I trials. Anterior segment persistent — keratitic precipitates, foreign body scar; transient — subepithelial opacity, conjunctional haemorrhage, aberrant eyelashes, blepharitis, jaundice; Iris transient — nodules; Lens persistent — nuclear sclerosis and cataract; transient — nuclear sclerosis; Vitreous transient - floaters; Fundus transient - Hollenhurst plaque, posterior vitreous detachment, minimal venous tortuosity, microaneurysm, supranasal peripapular myelin fibre. No change, patients did not show the condition at baseline or during the trial, or patients showed the condition at baseline and had the condition either persistently or transiently during the trial; Resolved, patients showed the condition at baseline but not during the trial; Persistent, patients did not have the condition at baseline but developed a persistent condition during the trial; Transient, patients did not have the condition at baseline but developed the condition transiently during the trial. ${ }^{\mathrm{a}}$ Trials 11 and 12 only, ${ }^{\mathrm{b}}$ Trial 5 data included.

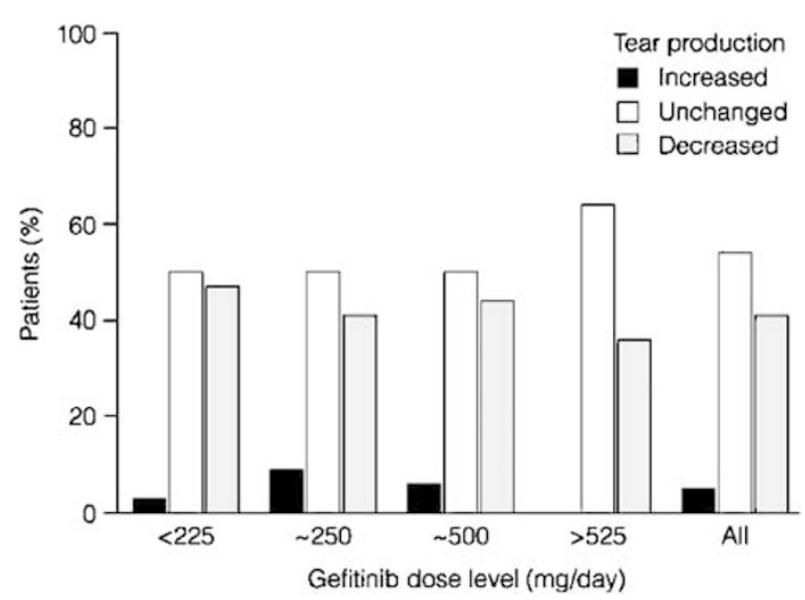

Figure 3 Worst change from baseline in Schirmer's test at any time during Phase I trials.

withdrawal due to disease progression. Five patients had corneal erosions that were considered by the investigator to be related to gefitinib treatment. One was a 70-year-old man receiving gefitinib $800 \mathrm{mg} /$ day for prostate cancer. He had dry eyes at baseline (Schirmer's values: right $0-5 \mathrm{~mm}$, left $>5-10 \mathrm{~mm})$. By Day 42 his condition had worsened to NCI-CTC grade 2, requiring artificial tears, and by Day 49 he developed grade 2 conjunctivitis. After two treatment periods, gefitinib therapy was interrupted and reduced to $600 \mathrm{mg} /$ day due to an NCI-CTC grade 3 skin rash. During the third treatment period, he experienced eye discomfort and made an unscheduled visit to an ophthalmologist complaining of eye pain and redness. Slit-lamp examination revealed a serious NCICTC grade 3 corneal epithelial breakdown with a 3-mm central defect; the patient was withdrawn from the trial. Despite curative treatment, the defect increased to $6.5 \mathrm{~mm}$. A review of photomicrographs of the defect site revealed an unreported ingrowing ectopic eyelash of the upper lid directly opposing the site of the corneal defect. The erosion was $95 \%$ healed 3 days after removal of the lash and subsequently healed completely. After 2 months, the patient developed an ingrowing lash on the lower lid. This was removed and was not associated with 
Table 3 Ocular adverse events in Phase I trials, $n(\%)$

\begin{tabular}{|c|c|c|c|c|c|}
\hline \multirow[t]{2}{*}{ Adverse events } & \multicolumn{5}{|c|}{ Gefitinib dose level (mg/day) } \\
\hline & $\begin{array}{c}<225 \\
(n=42)\end{array}$ & $\begin{array}{c}\sim 250 \\
(n=69)\end{array}$ & $\begin{array}{c}\sim 500 \\
(n=44)\end{array}$ & $\begin{array}{c}>525 \\
(n=66)\end{array}$ & $\begin{array}{c}\text { All } \\
(n=221)\end{array}$ \\
\hline Total patients ${ }^{\mathrm{a}}$ & $15(35.7)$ & $20(29.0)$ & $12(27.3)$ & $21(31.8)$ & $68(30.8)$ \\
\hline Conjunctivitis & $9(21.4)$ & $10(14.5)$ & $4(9.1)$ & 9 (13.6) & $32(14.5)$ \\
\hline Dry eyes & $2(4.8)$ & $4(5.8)$ & $1(2.3)$ & $11(16.7)$ & $18(8.1)$ \\
\hline Visual disturbances $^{\mathrm{b}}$ & $6(14.2)$ & $9(13.0)$ & $1(2.3)$ & $0(0.0)$ & $16(7.2)$ \\
\hline Blepharitis & $3(7.1)$ & $0(0.0)$ & $2(4.5)$ & $1(1.5)$ & $6(2.7)$ \\
\hline Superficial punctate keratopathy & $0(0.0)$ & $2(2.9)$ & $0(0.0)$ & $2(3.0)$ & $4(1.8)$ \\
\hline Corneal erosion & $0(0.0)$ & $0(0.0)$ & $2(4.5)$ & $2(3.0)$ & $4(1.8)$ \\
\hline Eye pain & $2(4.8)$ & $0(0.0)$ & $2(4.5)$ & $0(0.0)$ & $4(1.8)$ \\
\hline Trichiasis & $0(0.0)$ & $0(0.0)$ & $0(0.0)$ & $4(6.1)$ & $4(1.8)$ \\
\hline Eye disorder ${ }^{c}$ & $2(4.8)$ & $0(0.0)$ & $0(0.0)$ & $1(1.5)$ & $3(1.4)$ \\
\hline Subconjunctival haemorrhage & $0(0.0)$ & $2(2.9)$ & $0(0.0)$ & $1(1.5)$ & $3(1.4)$ \\
\hline Corneal opacity & $0(0.0)$ & $1(1.4)$ & $0(0.0)$ & $0(0.0)$ & $1(0.5)$ \\
\hline Hyperlacrimation & $1(2.4)$ & $0(0.0)$ & $0(0.0)$ & $0(0.0)$ & $1(0.5)$ \\
\hline Cataract & $0(0.0)$ & $0(0.0)$ & $0(0.0)$ & $1(1.5)$ & $1(0.5)$ \\
\hline Glaucoma & $0(0.0)$ & $0(0.0)$ & $1(2.3)$ & $0(0.0)$ & $1(0.5)$ \\
\hline Macular oedema & $0(0.0)$ & $0(0.0)$ & $0(0.0)$ & $1(1.5)$ & $1(0.5)$ \\
\hline Uveitis & $1(2.4)$ & $0(0.0)$ & $0(0.0)$ & $0(0.0)$ & $1(0.5)$ \\
\hline Unilateral scotomata & $0(0.0)$ & $0(0.0)$ & $1(2.3)$ & $0(0.0)$ & $1(0.5)$ \\
\hline Floaters & $0(0.0)$ & $1(1.4)$ & $0(0.0)$ & $0(0.0)$ & $1(0.5)$ \\
\hline
\end{tabular}

a Patients may have had more than one adverse event.

bIncludes blurred vision, abnormal vision, hemianopia (due to metastases) and photophobia.

cPingueculae, iris nodules, corneal epithelial hyperplasia.

a corneal lesion. Two patients receiving gefitinib 600 and $800 \mathrm{mg} /$ day also had corneal defects of NCI-CTC grades 2 and 3 , respectively, which were associated with abnormal lashes. In both cases, the corneal defects healed rapidly after removal of the aberrant lashes. In one patient receiving gefitinib $400 \mathrm{mg} /$ day, the NCI-CTC grade 1 erosion resolved after treatment cessation, while in one patient (gefitinib $525 \mathrm{mg} /$ day), the grade 1 erosion resolved and the patient continued on treatment without recurrence. A further two patients reported ingrowing and abnormally long eyelashes, respectively (gefitinib 600 and $1000 \mathrm{mg} /$ day), which were removed before any potential damage to the eye could occur. Corneal erosions and aberrant eyelashes were only observed at gefitinib doses of $\geqslant 400 \mathrm{mg} /$ day.

\section{Phase II trials}

A total of 425 patients with pretreated advanced NSCLC were treated in the two Phase II trials (Table 4).

In these two studies, more than 500 slit-lamp examinations were performed. Eye symptoms/events were experienced by $102(23.9 \%)$ patients $(22.9 \%$ at $250 \mathrm{mg} /$ day and $25.0 \%$ at $500 \mathrm{mg} /$ day) during the trial period. The majority of these events were mild (grade 1 , $77 \%$ ) or moderate (grade 2, 22\%). There were only two NCI-CTC grade 3 events reported, neither of which was considered by the investigator to be related to gefitinib treatment. The most common ocular adverse events seen in these trials were conjunctivitis $(8.2 \%)$, dry eyes (4.0\%), blepharitis (3.5\%), and visual disturbance (3.1\%), which included blurred vision, bilateral hemianopia, and photophobia (Table 5). There appeared to be a slight dose effect on conjunctivitis and events reported as corneal erosions and trichiasis. The remaining ocular adverse events, including those reported as superficial punctate keratopathy, did not show any evidence of being related to gefitinib dose.

Of the 35 reports of conjunctivitis (30 at NCI-CTC grade 1 and five at grade 2), $17(48.6 \%)$ were thought by the investigator to be drug-related $(2.4 \%$ at $250 \mathrm{mg}$ /day and $5.9 \%$ at $500 \mathrm{mg} /$ day). Conjunctivitis resolved in 28 of the 35 patients during the treatment period or after treatment was withdrawn. In the remaining seven patients, the event was ongoing at the time of withdrawal due to disease progression.

Superficial punctate keratopathy was observed in four patients at $250 \mathrm{mg} /$ day and six patients at $500 \mathrm{mg} /$ day. These events were all NCI-CTC grade 1, except for two grade 2 events at $500 \mathrm{mg} /$ day. Five patients developed corneal erosions, four of whom were receiving the $500 \mathrm{mg} /$ day dose. Two of these patients on $500 \mathrm{mg} /$ day had NCI-CTC grade 1 erosions, one of which was not considered by the investigator to be related to gefitinib due to the patient's medical history. One patient with a history of corneal dystrophy and macular degeneration 
Table 4 Patient demography in the Phase II trials

\begin{tabular}{lccc}
\hline & \multicolumn{3}{c}{ Gefitinib dose level $(\mathrm{mg} /$ day $)$} \\
\cline { 2 - 4 } & $\begin{array}{c}250 \\
(n=205)\end{array}$ & $\begin{array}{c}500 \\
(n=220)\end{array}$ & $\begin{array}{c}\text { All } \\
(n=425)\end{array}$ \\
\hline Age, median (range), years & 60 & 60 & 60 \\
& $(28-85)$ & $(30-80)$ & $(28-85)$ \\
Male/female, $\%$ & $67 / 33$ & $60 / 40$ & $64 / 36$ \\
Performance status & $18 / 66 / 16$ & $16 / 67 / 17$ & $17 / 67 / 16$ \\
$0 / 1 / 2, \%$ & & & \\
& & & \\
Previous cancer treatment, $n(\%)$ & & & \\
1 chemotherapy regimen & $59(28.8)$ & $60(27.3)$ & $119(28.0)$ \\
2 chemotherapy regimens & $87(42.2)$ & $94(42.7)$ & $181(42.5)$ \\
3 chemotherapy regimens & $31(15.0)$ & $41(18.6)$ & $41(18.6)$ \\
$\geqslant 4$ chemotherapy regimens & $28(13.6)$ & $25(11.4)$ & $125(29.3)$ \\
Radiotherapy & $125(60.9)$ & $122(55.5)$ & $247(58.1)$ \\
Surgery & $91(44.2)$ & $87(39.5)$ & $178(41.8)$ \\
Other & $3(1.5)$ & $9(4.1)$ & $12(2.8)$ \\
& & & \\
Days on gefitinib, mean & 79.6 & 73.7 & 76.6 \\
\hline
\end{tabular}

Table 5 Ocular adverse events seen in Phase II trials, $n$ (\%)

\begin{tabular}{lrrr}
\hline Adverse event $^{\text {a }}$ & \multicolumn{3}{c}{ Gefitinib dose level $(\mathrm{mg} /$ day $)$} \\
\cline { 2 - 4 } & $\begin{array}{c}250 \\
(n=205)\end{array}$ & $\begin{array}{c}500 \\
(n=220)\end{array}$ & $\begin{array}{c}\text { All } \\
(n=425)\end{array}$ \\
\hline Conjunctivitis & $15(7.3)$ & $20(9.1)$ & $35(8.2)$ \\
Dry eyes & $8(3.9)$ & $9(4.1)$ & $17(4.0)$ \\
Blepharitis & $8(3.9)$ & $7(3.2)$ & $15(3.5)$ \\
Visual disturbance & $7(3.4)$ & $6(2.7)$ & $13(3.1)$ \\
Superficial punctate & $4(2.0)$ & $6(2.7)$ & $10(2.4)$ \\
keratopathy & & & \\
Corneal erosion & $1(0.5)$ & $4(1.8)$ & $5(1.2)$ \\
Eye pain & $5(2.4)$ & $3(1.4)$ & $8(1.9)$ \\
Hyperlacrimation & $3(1.5)$ & $5(2.3)$ & $8(1.9)$ \\
Diplopia & $2(1.0)$ & $2(0.9)$ & $4(0.9)$ \\
Trichiasis & $1(0.5)$ & $5(2.3)$ & $6(1.4)$ \\
Cataract & $1(0.5)$ & $1(0.5)$ & $2(0.5)$ \\
Anisocoria & $1(0.5)$ & $1(0.5)$ & $2(0.5)$ \\
Bilateral macular oedema & $1(0.5)$ & $0(0.0)$ & $1(0.2)$ \\
Unilateral scotomata & $0(0.0)$ & $1(0.5)$ & $1(0.2)$ \\
Miosis & $0(0.0)$ & $1(0.5)$ & $1(0.2)$ \\
Ptosis & $0(0.0)$ & $1(0.5)$ & $1(0.2)$ \\
Subconjunctival & $0(0.0)$ & $1(0.5)$ & $1(0.2)$ \\
haemorrhage & & & \\
\hline
\end{tabular}

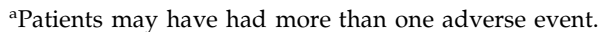

${ }^{\mathrm{b}}$ Includes blurred vision, bilateral hemianopia and photophobia.

had a drug-related NCI-CTC grade 2 corneal erosion that resolved in 14 days following temporary withdrawal of gefitinib, while the fourth patient had a grade 3 corneal erosion that was considered to be traumatic and unrelated to trial treatment. The patient on $250 \mathrm{mg} /$ day gefitinib had an NCI-CTC grade 2 corneal erosion that resolved 3 days after therapy ceased.
Events of dry eyes and blepharitis were mostly NCI-CTC grade 1 with a small number of grade 2 events. There was no difference in terms of frequency, causality, or severity between the 250 and $500 \mathrm{mg}$ /day doses. In 65 and $93 \%$ of events of dry eyes and blepharitis, respectively, the investigator considered the event to be possibly related to trial treatment.

Six patients had mild-to-moderate trichiasis, one at $250 \mathrm{mg} /$ day and five at $500 \mathrm{mg} /$ day. One of these patients reported trichiasis as an adverse event on Days 43 and 120 of treatment. On Day 43 it was associated with NCI-CTC grade 2 blepharitis and ulceration of eyelid skin, and on Day 120 with grade 2 blepharitis.

\section{Discussion}

The baseline data in these trials revealed that, in an asymptomatic population, events on the ocular surface are identified during frequent and intensive monitoring. However, the majority of these were found to be transient.

Gefitinib is the first in a new class of biologically targeted anticancer agents that inhibit the EGFR. It has shown unprecedented antitumour activity in heavily pretreated patients with advanced NSCLC and is generally well tolerated, with the most common adverse events being mild diarrhoea and skin rash. It is not typically associated with the haematological side effects seen with conventional chemotherapy. ${ }^{12,13}$ Gefitinib has now been licensed for use in NSCLC in 24 countries, including the USA, Australia, Canada, Switzerland, and Japan, and, as of March 2004, has been used in more than 132,000 patients. For many oncologists, novel targeted therapies such as gefitinib represent the future of anticancer treatment; therefore, it is important that all associated safety issues, including potential ophthalmological toxicity, are fully understood.

Gefitinib appears to be unrelated to any significant ocular events at the doses used in these studies. There appears to be an increased likelihood of dry eyes at doses $\geqslant 525 \mathrm{mg} /$ day. In the Phase I trials there was no evidence of any consistent or drug-related ophthalmological toxicity and many of the events observed were thought to reflect the variance within a normal population. The most clinically significant ophthalmological events reported in these trials were infrequent reversible corneal erosions, which all occurred at doses higher than the currently recommended dose of gefitinib ( $250 \mathrm{mg} /$ day).

Furthermore, several of these events were associated with abnormal eyelash growth and were heralded by symptoms of pain or discomfort. The corneal erosions healed rapidly on removal of the abnormal lashes. Patients could readily monitor this condition and lashes can be removed before any corneal damage occurs. 
Interestingly, these trials did not reveal any asymptomatic findings representative of those detected in preclinical animal studies (rough appearance of cornea, diffuse corneal translucency, and corneal atrophy).

These results are supported by data from the two large Phase II trials. Gefitinib at $250 \mathrm{mg} /$ day has been received by more than 46,000 patients as part of the Expanded Access Programme that allows gefitinib to be given on a compassionate basis to cancer patients with no other treatment options. A small number of ocular events has been reported, which were similar to those seen in the gefitinib trial programme, but there has been no evidence of significant ocular toxicity in the Expanded Access Programme, thus supporting the data from the clinical trials.

Mild conjunctival hyperaemia, mild, and reversible superficial punctate keratopathy, blepharitis, and trichiasis were found in a small percentage of patients in the clinical trial programme. In general, these findings are nonspecific and could be caused by any of several factors besides gefitinib, including age or pre-existing keratoconjunctivitis sicca. One possible explanation for these minimal ocular findings is pre-existing dry-eye syndrome due to damage to the tear-film producing ocular structures caused by previous chemotherapy. Any such damage could have been exacerbated by the use of an EGFR-TKI. EGFR expression has been demonstrated in the ocular surface epithelia in humans, particularly in the basal epithelial cells, which have the greatest proliferative potential. ${ }^{4}$ Furthermore, it has been shown that the expression of EGFR in the conjunctival epithelium is significantly greater in eyes with keratoconjunctivitis sicca than in normal eyes. ${ }^{16}$ The increased expression of these receptors has been positively correlated with ocular surface dye staining. It has been suggested that the balance of cytokines in the tear fluid and conjunctival epithelium is altered in Sjögren's syndrome and that the severity of keratoconjunctivitis sicca increases as tear fluid EGF concentration decreases. ${ }^{17}$ Thus, it is possible that in patients who have pre-existing keratoconjunctivitis sicca, addition of an EGFR-TKI may exacerbate the signs and symptoms of this condition. The prophylactic use of topical lubricating drops (artificial tears) would be an appropriate way to prevent mild keratoconjunctivitis sicca in patients predisposed to this condition.

Meibomitis (inflammation of the sebaceous meibomian glands at the base of the lashes) was seen in a few patients in the clinical trial programme and was generally mild and reversible. An acneiform rash on the face and body is a well-known side effect of most EGFRTKIs. ${ }^{9}$ It is possible that meibomian gland inflammation and overactivity, like the acneiform rash, can occur secondary to gefitinib. Meibomitis may be a contributing factor to other ocular findings observed in the current study, such as trichiasis, mild superficial keratopathy, conjunctival hyperaemia, and dry-eye syndrome.

In conclusion, results from the comprehensive ophthalmological monitoring performed in these Phase I and II trials, including more than 1300 slit-lamp examinations, did not reveal any serious adverse ocular events representative of those seen in preclinical studies. Moreover, with the exception of minor and treatable superficial punctate keratopathy, dry eyes, blepharitis, conjunctivitis, and trichiasis in a few patients, no consistent drug-related ocular toxicity was seen in these trials. Gefitinib was associated with far less ocular toxicity than conventional chemotherapy. ${ }^{18}$ There is therefore no evidence to suggest a need for routine ophthalmological surveillance of patients receiving gefitinib. As is the case with any chemotherapeutic agent, patients ought to be made aware that they should seek advice if they develop any new ocular symptoms while receiving this novel drug.

As large-scale ophthalmological monitoring is not routinely carried out in clinical trials, there are no standard procedures for undertaking such screening. The methodology for assessing the ocular effects of gefitinib used in these studies may assist others in planning their approach when studying other novel therapeutic agents that may be expected to have ocular effects. Furthermore, the results seen with gefitinib, the first in a new class of small molecule EGFR-TKIs, may go some way towards predicting the effects of other similar agents currently under development.

'Iressa' is a trademark of the AstraZeneca group of companies.

\section{References}

1 Yano S, Kondo K, Yamaguchi M, Richmond G, Hutchison $\mathrm{M}$, Wakeling A et al. Distribution and function of EGFR in human tissue and the effect of EGFR tyrosine kinase inhibition. Anticancer Res 2003; 23: 3639-3650.

2 Breider MA. Irreversible inhibition of ErbB receptor family in rats results in epithelial atrophy and ulcerative dermatitis. Pharmacol Exp Ther 2000; 41: 493.

3 Hidalgo M, Siu LL, Nemunaitis J, Rizzo J, Hammond LA, Takimoto $\mathrm{C}$ et al. Phase I and pharmacologic study of OSI774, an epidermal growth factor receptor tyrosine kinase inhibitor, in patients with advanced solid malignancies. J Clin Oncol 2001; 19: 3267-3279.

4 Liu Z, Carvajal M, Carraway CA, Carraway K, Pflugfelder SC. Expression of the receptor tyrosine kinases, epidermal growth factor receptor, ErbB2, and ErbB3, in human ocular surface epithelia. Cornea 2001; 20: 81-85.

5 Wilson SE, He YG, Weng J, Zieske JD, Jester JV, Schultz GS. Effect of epidermal growth factor, hepatocyte growth factor, and keratinocyte growth factor, on proliferation, motility 
and differentiation of human corneal epithelial cells. Exp Eye Res 1994; 59: 665-678.

6 Wilson SE, Liang Q, Kim WJ. Lacrimal gland HGF, KGF, and EGF mRNA levels increase after corneal epithelial wounding. Invest Ophthalmol Vis Sci 1999; 40: 2185-2190.

7 Carpenter G, Wahl MI. The epidermal growth factor family. Hand Exp Pharmacol 1990; 951: 69-171.

8 Schultz G, Cipolla L, Whitehouse A, Eiferman R, Woost P, Jumblatt M. Growth factors and corneal endothelial cells: III. Stimulation of adult human corneal endothelial cell mitosis in vitro by defined mitogenic agents. Cornea 1992; 11: 20-27.

9 Baselga J, Rischin D, Ranson M, Calvert H, Raymond E, Kieback DG et al. Phase I safety, pharmacokinetic, and pharmacodynamic trial of ZD1839, a selective oral epidermal growth factor receptor tyrosine kinase inhibitor, in patients with five selected solid tumor types. J Clin Oncol 2002; 20: 4292-4302.

10 Ranson M, Hammond LA, Ferry D, Kris M, Tullo A, Murray PI et al. ZD1839, a selective oral epidermal growth factor receptor-tyrosine kinase inhibitor, is well tolerated and active in patients with solid, malignant tumors: results of a phase I trial. J Clin Oncol 2002; 20: 2240-2250.

11 Herbst RS, Maddox AM, Rothenberg ML, Small EJ, Rubin $\mathrm{EH}$, Baselga $\mathrm{J}$ et al. Selective oral epidermal growth factor receptor tyrosine kinase inhibitor ZD1839 is generally welltolerated and has activity in non-small-cell lung cancer and other solid tumors: results of a phase I trial. J Clin Oncol 2002; 20: 3815-3825.

12 Fukuoka M, Yano S, Giaccone G, Tamura T, Nakagawa K, Douillard J-Y et al. Multi-institutional randomized phase II trial of gefitinib for previously treated patients with advanced non-small-cell lung cancer. J Clin Oncol 2003; 21: 2237-2246.

13 Kris MG, Natale RB, Herbst RS, Lynch Jr TJ, Prager D, Belani CP et al. Efficacy of gefitinib, an inhibitor of the epidermal growth factor receptor tyrosine kinase, in symptomatic patients with non-small cell lung cancer. A randomized trial. JAMA 2003; 290: 2149-2158.

14 National Cancer Institute Cancer Therapy Evaluation Program. Common toxicity criteria manual. Common toxicity criteria, version 2. http://ctep.info.nih.gov. April 1999.

15 International Conference on Harmonisation of Technical Requirements for Registration of Pharmaceuticals for Human Use. The International Conference on Harmonisation (ICH) Guidelines, E2A: Clinical Safety Data Management: Definitions and Standards for Expedited Reporting. http://www.ich.org. October 1994.

16 Liu Z, Carvajal M, Carothers Carraway CA, Carraway KL, Pflugfelder SC. Increased expression of the type 1 growth factor receptor family in the conjunctival epithelium of patients with keratoconjunctivitis sicca. Am J Ophthalmol 2000; 129: 472-480.

17 Pflugfelder SC, Jones D, Ji Z, Afonso A, Monroy D. Altered cytokine balance in the tear fluid and conjunctiva of patients with Sjogren's syndrome keratoconjunctivitis sicca. Curr Eye Res 1999; 19: 201-211.

18 al-Tweigeri T, Nabholtz JM, Mackey JR. Ocular toxicity and cancer chemotherapy. A review. Cancer 1996; 78: 1359-1373. 